\title{
OBITUARY \\ Obituary for Air Marshal Amarjit Singh Chahal (25 December 1929-21 June 2015)
}

Spinal Cord (2015) 53, 648; doi:10.1038/sc.2015.141; published online 28 July 2015

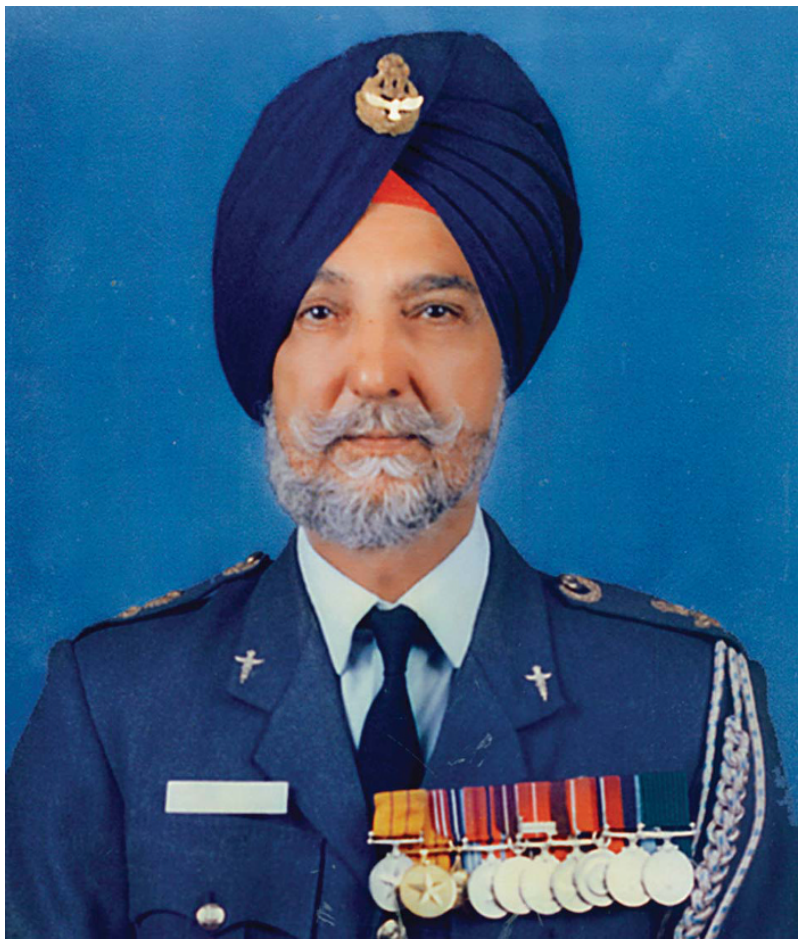

Air Marshal Amarjit Singh Chahal was born on 25 December 1929 in Patiala, India. After receiving his Medical degree from Government Medical College, Amritsar in 1951, he served as a house surgeon in the Department of Clinical Surgery for 1 year and then served as Casualty Medical Officer and Demonstrator in Anatomy until 1953. In September 1953, he was selected for permanent Commission in the Indian Army Medical Corps, was trained for surgery and obtained his Masters in Surgery degree from Punjab University in 1965.

He was posted as Second-in-Command and Chief Surgeon at the Artificial Limb Centre, Pune from 1966 to 1970. In 1969, he was selected for training in spinal surgery as a Colombo Plan Fellow. He worked as a Senior Fellow at the Royal Perth Hospital and Austin Hospital in Australia. He passed the Fellowship Exams of the Royal College of Surgeons of Australia in 1970. On completion of his Fellowship, he was posted to the Military Hospital, Khadki, Pune in 1971, where he was charged with the development of the first Spinal Cord Injury Centre for the Armed Forces. During this time, he pioneered the development of a Paraplegic Home in 1974 - the first of its kind in India. In 1978, he was appointed as Professor of
Orthopedics at the Armed Forces Medical College, Pune. $\mathrm{He}$ established the Department of Orthopedics during his tenure there, and was the first Head of Department.

In 1983, as a Brigadier, he became a Consultant in Orthopedics at Base Hospital, Delhi Cantonment, and, in 1985, he became the Deputy Director of Medical Services 33 Corps HQ in North Bengal. He was promoted to the rank of Major General and took over as the Director of Medical Services, Northern Command of the Indian Army in January 1986, and for Southern Command in October 1986. He participated in different wars.

On the basis of an extensive experience and knowledge, he was recognized around the world as an expert in the treatment of tuberculosis of the spine.

In 1988, he was promoted to the rank of Air Marshal and appointed as the Director General of Air Force Medical Services. On his retirement, he joined and helped establish the first civilian Spinal Injury Centre at Vasant Kunj in New Delhi. He was the first Director General of the hospital and in 1995 became a member of the Board of Directors of the Indian Spinal Injuries Centre. He trained several young orthopedic surgeons in the field of Spinal Surgery and Rehabilitation. He organized the Annual Meeting of International Spinal Cord Society (ISCoS, formerly IMSoP) Conference as the Organizing Secretary in September 1995 at Delhi. He was a member of the ISCoS committee from 1980 to 1988 and served as the Vice President of the Society for 3 years and as an Editor for the Journal for the next 10 years. He published numerous scientific papers in peerreviewed journals. He spoke extensively on paraplegia, non-union of fractures and tuberculosis of the spine in USA, England, Australia, Japan, Korea, Indonesia, India and many other nations.

He was an active sportsman and held college colors in field hockey in 1949-1950. Later, he played tennis and was an avid golfer.

He was honored by the nation with the Vishisht Seva Medal and the Ati Vishisht Seva Medal, two of the highest levels of honors. He was given a Lifetime Achievement Award by his alma mater-Amritsar Medical College. He was appointed Physician to the President of India.

Air Marshal Amarjit Singh Chahal lived in Chandigarh from 2007 and was a visiting Senior Orthopedics Consultant at Silver Oaks Hospital, Chandigarh. He passed away after a brief illness on 21 June 2015. He is greatly missed by his wife, daughter, two sons and seven grandchildren. He is also missed by his students, patients, colleagues and admirers. The ISCoS Society will never forget him as one of the most important spinal cord specialists of his time and a much valued member of the group.

HS Chhabra Spine services, Indian Spinal Injury Centre, New Delhi, India E-mail: drhschhabra@isiconline.org 